\title{
Ethics of Belief, Trust and Epistemic Value: The Case of the Scientific Controversy Surrounding the Measles Vaccine ${ }^{1}$
}

\author{
Romy Sauvayre \\ University of Clermont Auvergne
}

\begin{abstract}
An anxious belief that the vaccine against measles may cause autism in children has circulated since 1998. This belief has resulted in a worldwide reduction of vaccination coverage. Between 1998 and 2004, the scientific community was engaged in an intense debate over proof of vaccine safety. The question is then to examine the justification and the acceptance of this anxious belief by scientists, journalists, and parents. What are the epistemic obligations of individuals when scientific evidence is lacking? Therefore, the ethics of belief will be questioned through a contemporary socio-historical case study because it permits the examination of belief, knowledge and confidence mechanisms, and the attribution of epistemic values when it is difficult to produce indisputable evidence.
\end{abstract}

Keywords: ethics of belief, values, confidence, belief, justification, vaccine, autism, scientific controversy

\section{INTRODUCTION: ETHICS OF BELIEF AND THE MECHANISMS OF JUSTIFICATION}

According to Clifford (1877), justification of beliefs would be associated with an epistemic obligation: one should not believe without sufficient evidence to do so. Clifford then sets out, in a normative article imbued with puritanism, the foundations of the ethics of belief. According to him, without this ethical approach, humanity would become gullible. Alston (1988), in his deontological conception of justification, clarifies Clifford's maxim by stating that one should not adhere to beliefs that are likely to be false and that one should only adhere to beliefs that are highly likely to be true. The notions of "truth" and "evidence" are therefore the basis of belief ethics. Believing and thus adhering to a belief requires holding a proposition to be true (Engel, 2006). In order to do this, it is reasonable and ethical to base this adherence on evidence. However, what about this justification when the scientific community disputes the notion of proof? Evidence is so central to Clifford's prescription that we propose to explore the mechanisms of adherence based on a socio-historical case in which three social actors (scientists, journalists and British citizens) will apprehend the evidence at their disposal differently and thus adhere to contrary propositions. The ethics of belief will therefore not be approached from its moral side, but from its epistemic side, which will lead us to confront Clifford's prescriptive statement with a scientific controversy with the particularity of making it difficult to apply it during a given period. In order to do this, we will neither make value judgements (Weber, 2003), nor epistemic judgements about the beliefs and knowledge exposed, in order to focus on the reasons for adherence by social actors (Boudon, 2003). From this perspective, the actor is considered rational, in the flexible sense of the term, and does not believe by his will alone (James, 2005), but because he has good reasons to adhere to the beliefs he holds to be true. These reasons are notably based on the investigations he has carried out and on his accumulated experience (Sauvayre, 2017). 
By taking the point of view of British scientists, journalists and citizens in turn, we will explain the mechanisms of belief, focusing in particular on the subjectivity and variability of the epistemic values attributed to a given proposal or mediator. First, we will describe in detail the chronology of events surrounding the scientific controversy generated by the announcement of an anxiety-provoking discovery linking the MMR vaccine (composed of an attenuated form of the measles, mumps and rubella viruses) and autism. Secondly, we will analyse the adherence to this discovery by British journalists and then by the British population. Finally, we will return to these events in order to question the mechanisms of belief, knowledge, trust and the differentiated attribution of epistemic values in a context where proof was difficult to establish. Justification and ethics of belief will thus be enlightened by a concrete case, namely the "Wakefield case".

\section{THE WAKEFIELD CASE: FROM SCIENTIFIC CONTROVERSY TO SUSPICION OF FRAUD}

On 26 February 1998, a press conference was held at the Royal Free Hospital in London (Mnookin, 2017). Andrew Wakefield, a gastric surgeon by training, was then practising in this hospital. Together with several colleagues and Arie Zuckerman, Dean of the Faculty of Medicine, he revealed the results of their study, which appeared two days later in the medical journal The Lancet ${ }^{2}$ (Wakefield et al., 1998). At the press conference, Wakefield announced that the study showed a link between the MMR vaccine, the development of a new gastric disorder and autism. Sarah Boseley (2002), a health editor with The Guardian newspaper, said in her retrospective article that she did not perceive this announcement as a partial scientific belief still awaiting confirmation from the scientific community, but as a "fact" in her own words. Indeed, it was a fact in her eyes because a respectable scientific institution published an article in one of the world's leading journals in which a link between the MMR vaccine, a new gastric disorder and autism was established. For the general public, widely informed by journalists, this study also revealed a particularly alarming fact. However, for the scientific community, and several of Wakefield's co-authors, the conclusions of the study were abusive and needed to be verified by further studies. The epistemic status of Wakefield's statement, and its reception, differed between scientists and non-scientists: the evidence was sufficient to generate buy-in from non-scientists, but not from many scientists.

Several years of scientific controversy followed, which was widely covered by journalists (Millward, 2019), and thus particularly followed by the British public. Between 1996 and 1998, 60\% of the published studies invalidated Wakefield's thesis and $40 \%$ confirmed $^{3}$ it. In the years that followed, scientific debates continued to be reported in the media. Experts (researchers, doctors, epidemiologists, etc.) attacked the methodological weaknesses of the opposite camp: some criticised the small sample size of the clinical study conducted by Wakefield (12 children) (Payne and Mason, 1998) and others criticised the lack of data specific to autistic children in epidemiological studies (Thrower, 2004). Wakefield responded to his critics by pointing out the methodological differences between clinical medicine and epidemiology (Wakefield, 1998). Between 1996 and 2001, 13 studies exploring the link between vaccines and autism were published (Institute of Medicine, 2004, 2012): 69\% invalidated Wakefield's thesis and 31\% confirmed it. The National Academies of Medicine, known as the Institute of Medicine (IOM) until 2015, will repeatedly assess the risks induced by the inoculation of vaccines, and in particular the supposed link between MMR vaccine and autism. Its 2001 report (Institute of Medicine, 2001) disqualified the work of Wakefield and colleagues (1998) by considering that they did not establish a causal link between the MMR vaccine and autism. However, given the limited knowledge available to the expert committee convened by the IOM, the report stated that it could not rule out the possible involvement of the MMR vaccine in the development of autism in a small sample of children. The scientific controversy was therefore still ongoing and did not allow the scientists to reach a decision. In January, several British newspapers, including the Daily Mail, supported Wakefield (Deer, 2011a) and continued to cover the debate extensively (Fitzpatrick, 2004; Millward, 2019); in October, the Royal Free Hospital asked the surgeon to resign; in December, Tony Blair, then Prime Minister of the United Kingdom, refused to reveal whether or not he had vaccinated his son Leo, then under the age of two (Womack, 2001). The open debate about Leo Blair continued until early 2002. At the same time, studies by John O'Leary (Martin, Uhlmann, Killalea, Sheils, et al., 2002; Uhlmann et al., 2002), a 
pathologist at Trinity College Dublin, were widely reported in the British media. These studies, one of which was co-authored by Wakefield, showed that $82-95 \%$ of children had traces of measles in their intestinal tissues following inoculation of the vaccine. This work confirmed in part the hypothesis that Wakefield had been developing for several years, namely that the virus would be deposited in the intestine and then migrate to the brain where it would cause neurological damage, particularly autism. In June 2003 and again in March 2004, two quantitative studies published by Mark R. Geier and David A. Geier (2003, 2004) confirmed more directly the link between the MMR vaccine and autism. These studies, published in unclassified journals by the Journal Citation Report (JCR), were very quickly criticised by the scientific community. Indeed, several experts pointed out the shortcomings of the method used, which provided uninterpretable results (Cox, 2003; Institute of Medicine, 2004) and the lack of expertise in immunology of these two independent researchers, who were also experts for the American courts (Cox, 2003). On February 14, 2004, the controversy surrounding the MMR vaccine continued, with several experts arguing in the "Correspondence" section of The Lancet (Elphinstone, 2004; Harvey, 2004; Murch, 2004; Thrower, 2004). However, scientific evidence was accumulating in favour of the safety of MMR. During this period (1996-2004), 24 studies were carefully reviewed by independent experts commissioned by the IOM: 75\% of these studies rejected Wakefield's thesis and the remaining $25 \%$ were disqualified for their inadequate methodology and inability to establish a clear causal link. It was therefore on 14 May 2004, in the report published by the IOM (2004), that all doubts were removed. The IOM stated that no link could be found between the MMR vaccine and autism. The scientific controversy thus ended in 2004, following six years of debate that was particularly well covered by the media.

The closure of this controversy was accelerated by the revelations of investigative journalist Brian Deer, who conducted an extensive investigation of Wakefield between 2003 and 2017 (Deer, n.d.). This investigation led him to reveal on 22 February 2004 in The Sunday Times (Deer, 2004) that Wakefield had, among other things, conducted particularly invasive examinations of children without the consent of the ethics committee and that he had a clear conflict of interest. In February 2004, Deer wrote an email to the General Medical Council (GMC), the British Medical Association, detailing the findings of his investigation and also informed the editor of The Lancet, Richard Horton, and five other members of the editorial team (Deer, 2011b). On 6 March, Horton (2004) issued a statement rejecting Deer's revelations point by point. On the same day, 10 out of 13 co-authors of Wakefield (Murch et al., 2004) retracted the conclusions of the article (Wakefield et al., 1998), rejecting the claim that the MMR vaccine was likely to develop autistic symptoms in vaccinated children. Not only was there media coverage of this retraction, but Wakefield refused to join his co-authors in co-authoring the retraction. In December 2004, the GMC announced public hearings into 11 possible professional misconduct by Wakefield and two of its co-authors John Walker-Smith and Simon Murch (Mnookin, 2011). The GMC investigation, which began in June 2007, concluded on January 28, 2010 with the disbarment of Wakefield and Walker-Smith ${ }^{4}$ from the medical profession. The GMC accused Wakefield of violating the fundamental principles of medical research and convicted him of "serious professional misconduct". These terms were widely reported in the media. Finally, in light of this judgment, on February 6, 2010, The Lancet magazine withdrew the article (Wakefield et al., 1998) that had initiated this long scientific-media controversy. Finally, in 2001, Deer published two articles in the highly respected British Medical Journal (BMJ), a competitor to The Lancet, reporting on its investigation and showing that Wakefield had committed scientific fraud by falsifying the data presented in its 1998 article. However, Wakefield has consistently denied any falsification of data.

The Wakefield case therefore lasted 12 years, from publication to the withdrawal of the article. There are two phases: a first phase of scientific controversy (1998-2004) on which the analysis of this article is based, and a second phase questioning Wakefield's professional ethics (2004-2010) and research ethics in general, which we will not discuss here.

Coming back to the confrontation of the epistemic obligation not to believe without proof (the ethics of belief) as prescribed by Clifford with the socio-historical case at hand, this brief history shows that the different social actors presented do not perceive proof in the same way. The epistemic value given to the proposition "MMR vaccine causes autism" differs whether one is a scientist, a journalist or any other British citizen. Following Wakefield's announcement and the publication of his article, how did each actor meet 
the epistemic obligations of not believing without proof when the scientific community failed to rule on this point between 1998 and 2004?

\section{MAINTENANCE OF ADHERENCE AND DECREASE IN VACCINATION COVERAGE}

Variation in vaccination rates is the most interesting marker of adherence to the scientific belief proposed by Wakefield, because to adhere to a proposal, it is necessary to hold it to be true or partially true (Sauvayre, 2012). Indeed, even partial adherence is likely to generate such doubt that it may lead parents to postpone, or even renounce, the vaccination of their young children. Between 1998 and 2004, immunisation coverage in the United Kingdom fell precisely among young children, from $91 \%$ to $81 \%$ (OECD, 2019). Doubt thus prevailed among many British people, since the confidence placed in Wakefield's work led many parents to be wary of the MMR vaccine. Figure 1 below shows that the fall in the vaccination rate is concomitant with the period of scientific controversy over the safety of the MMR vaccine. Let's take a closer look at the events that could cause this drop in immunization coverage.

\section{FIGURE 1 \\ MEASLES IMMUNISATION RATES FOR YOUNG BRITISH CHILDREN (MMR VACCINE) BETWEEN 1990 AND 2018 IN THE UNITED KINGDOM}

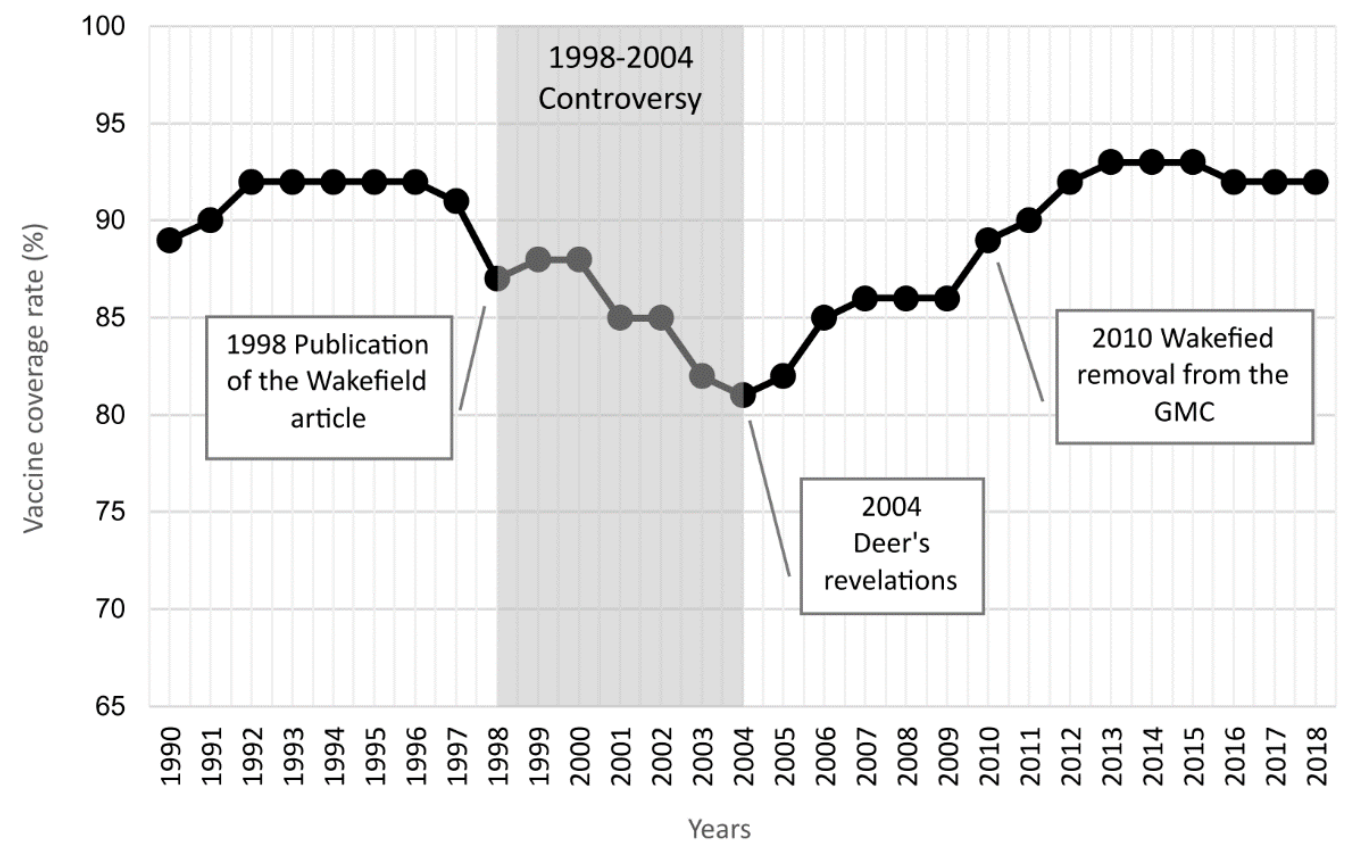

Source: OECD DATA (2019)

In 1998, following Wakefield's announcement linking the MMR vaccine, immunisation coverage fell by $4 \%$. This was the biggest drop in the UK. This drop was also seen globally. The trust placed in the medical institution (Royal Free Hospital), the magazine (The Lancet) and the media such as The Guardian or The Times led many Britons to take this scientific belief for granted, or even to consider it as knowledge or as a fact. However, for the scientific community, the Wakefield hypothesis remained a scientific belief, which was greeted with scepticism, and was likely to become scientific knowledge only once it had been confirmed by other studies (i.e. replicated). As mentioned in the previous section, two thirds of the scientific work published and taken into account by the IOM invalidated Wakefield's thesis. A probabilistic approach would lead to the conclusion that only scientists meet the epistemic obligations of membership. However, 
the publication of scientific work supporting the anti-vaccine thesis makes adherence to the contrary proposal equally justifiable. Both sides have ample evidence to justify their adherence.

In 2001, a second decrease of 3\% was noted. In 2003, the third and last major drop (3\%) was initiated by the media coverage (Cox, 2003; Fitzpatrick, 2004; Meikle, 2003) of the work of M. Geier and D. Geier (2003, 2004), demonstrating a link between the MMR vaccine and autism, more specifically by implicating the mercury contained in the vaccine. These events occurred at the same time as the spread of bovine spongiform encephalopathy (BSE), commonly known as "mad cow disease", which affected more than 180,000 animals between 1986 and 2000. During this period, the British government never ceased to reassure the population and encouraged them to consume beef by telling them that they were not at risk. However, in 1996, the government announced that BSE was likely to be transmitted to humans and announced the identification of Creutzfeldt-Jakob disease (human form of BSE) in 10 young Britons; in 2000, 144 Britons were affected (Greif and Merz, 2007). A total of 178 deaths were attributed to the disease in the UK (The National CJD Research \& Surveillance Unit, 2017). These events profoundly eroded the confidence of the British people in their government: they could not reasonably fully believe the government's assertion that vaccines were safe because they had experienced the flaws in this reassuring discourse only a short time before. The crisis also undermined the confidence of a quarter of the British people in science (Millward, 2019), since scientists had been saying until 1996 that BSE could not be transmitted to humans.

The likelihood of the veracity of Wakefield's thesis was therefore fuelled by several elements:

1) Although the IOM rejected Wakefield's conclusions, his report (Institute of Medicine, 2001) concluded that a link between the MMR vaccine and autism was possible;

2) The media covered more of the scientific controversy while supporting Wakefield;

3) O'Leary, a well-known researcher, provided scientific data (published in journals classified by the JCR) to support Wakefield's ${ }^{5}$ thesis and M. Geier and D. Geier more directly confirmed the anti-vaccine thesis;

4) Tony Blair's refusal to reveal his son's vaccination status reinforced the British people's mistrust of the government's reassuring rhetoric.

Even though the British media tried to balance the debates by presenting the provaccine and antivaccine theses, their influence in the vaccination crisis was particularly questioned (Fitzpatrick, 2004; Millward, 2019). This influence was exerted very early on when several journalists, both popular and recognised, working in several equally recognised media, raised their fears about the MMR vaccine (Fitzpatrick, 2004). It appears then that Wakefield's study, its media coverage, and the studies confirming the British surgeon's claims had consequences on the vaccination rate.

Each study confirming Wakefield's thesis had a greater effect on adherence to this anxiety-provoking scientific belief than studies challenging it. In sum, confidence in Wakefield's thesis was thus strengthened by the support of journalists, by the publication of concordant works, by a scientific discourse tinged with uncertainty, and by distrust of government discourse. The epistemic value of the dominant governmental and scientific discourse was mitigated by the mistrust that emerged from the BSE crisis, while the mistrust of supporters of Wakefield's thesis was reinforced. A weighting of the evidence provided by the different parties seems to be applied by each actor.

\section{ETHICS OF BELIEF, EPISTEMIC VALUE AND TRUST}

Let us now explore the mechanisms of this adherence by questioning the epistemic aspects of the ethics of belief of the three stakeholders: scientists, journalists and the general public. Let us posit that belief is a proposition that is held to be true or partially true, and for good reasons. In the field of the supposed safety of the MMR vaccine, how can a proposition be considered true or how can there be sufficient evidence to justify it? Since 2004, having sufficient evidence, the IOM $(2004,2012)$ has ruled in favour of the safety of the MMR vaccine. The scientific community is therefore very positive: the MMR vaccine does not cause autism following inoculation. In doing so, a standard of belief has been established among all those who trust science and attribute a strong epistemic value to its conclusions. Now, to quote Clifford, the ethic of 
belief imposes an epistemic obligation not to believe without sufficient evidence or, at the very least, to believe what has a high probability of being true. Anti-vaccine activists or sympathisers are thus disqualified by provocative proponents: not only do they believe against the obvious, but also against the enlightened majority. They thus seem, at first glance, to be transgressing their epistemic obligations. However, this obligation is temporally situated: it originated and was disseminated in 2004 in the report written by the esteemed IOM. In the previous period, 1998-2004, science was plunged into a scientific controversy preventing it from ruling in the absence of sufficient evidence. As described above, for six years (1998-2004), scientists disputed the notion of proof regarding the safety of the MMR vaccine. They disqualified the methodology applied by each other, considering that it could not provide sufficient evidence to justify their conclusions. For the proponents of clinical studies, the epidemiological studies were too crude to be enlightening. On the other hand, proponents of epidemiology argued that clinical studies used samples that were too small to be generalizable and to inform the debate. The epistemic value placed on either method thus varied according to the researchers, their research experience and the explanatory power attributed to a given method. In doing so, throughout the period when experts disagreed, the non-scientific individual did not have the means to decide on the safety of vaccines. His or her epistemic obligations dictated that he or she should postpone adherence and remain in the aporia. Yet, in practice, many Britons have adhered to Wakefield's thesis, an anxiety-provoking scientific belief that is now considered fraudulent, without sufficient evidence to do so.

The first step in the mechanisms of membership came when Wakefield gave his press conference to an audience of journalists in 1998. The declaration of a possible link between the MMR vaccine and autism announced by Wakefield, by means of a scientific study, was enough to transform a belief into a fact. There seems to be no doubt about the truth of this link among many journalists. In sum, the epistemic value placed on Wakefield's findings based on scientific study was so high as to generate immediate adherence. These journalists delegated the justification for their endorsement to the confidence they placed in his status as a surgeon, in that of his medical institution (Royal Free Hospital) and in the renowned journal The Lancet, which published him. These journalists rightly made this delegation on the basis of the knowledge they had at their disposal. The Lancet was highly regarded by researchers around the world (it is ranked by the JCR) and the Royal Free Hospital was a university hospital equally recognised by the profession. Wakefield had yet to be evaluated. The surgeon was already well known in the journalistic world since his previous study had already been covered in the media. On April 19, 1995, Wakefield published an article in which he linked the MMR vaccine to inflammation of the bowel (including Crohn's disease). The Economist reported on this on October 29, 1994, several months before publication, followed by The Guardian a few days after publication (Fitzpatrick, 2004). Wakefield had therefore already published in respected ${ }^{6}$ journals, which boosted the confidence of journalists in him. Therefore, when he claimed during the press conference that he had discovered a link between the MMR vaccine, a new inflammatory bowel disorder, and autism, he was trusted a priori. In short, their adherence was justified on the basis of the value placed on scientific studies, carried out within a renowned institution and validated by the expertise of a renowned journal. Finally, it was a discovery: as its name indicates, it was therefore a break with what was already known. Moreover, the content of this discovery had such implications for public health that journalists disseminated it very widely to the general public. They became the trusted mediators between Wakefield and the British parents who needed to vaccinate their children against measles.

The second stage of membership mechanisms is at the media interface between journalists and the general public, where journalists became mediators of belief and widely disseminated Wakefield's thesis to which they had previously adhered. Their readers, in turn, placed a priori trust in the journalistic treatment and in institutions such as The Guardian, The Times, The Daily Mail, The Sunday Times disseminating Wakefield's discovery. They, too, delegated the justification for their belief. A very practical question then arose for the British, who had to have their young children vaccinated twice (two doses of MMR vaccine). They could reserve judgment, but a decision was imperative for all these parents. The ethic of belief was confronted with the ethic of parenthood. What risks were these parents going to put their children at risk by choosing to vaccinate or not vaccinate their children? Wakefield's discovery, which was widely reported in the media, then created doubt about the safety of vaccines. There is no need for a high degree of adherence 
to this scientific belief for it to be considered probable and thus assign parents to reason. Deliberation was required to assess the risks. The forces at work were Wakefield, the innovative researcher listening to parents, widely reported by journalists, and the scientific community and the government intimidating the British to get vaccinated. The trust placed in Wakefield was built more on the basis of the mistrust that had previously accumulated during the BSE ("mad cow disease") scandal. The British government as well as the scientific community had failed to protect the public by claiming that meat consumption was safe. The hundred or so deaths attributed to Creutzfeldt-Jacob disease had eroded British confidence in science and in their government. Since parents determined the epistemic value of a belief based on the trust they placed in their mediator, this scandal reasonably led them to devalue the government's and scientists' warnings about refusing to vaccinate. From then on, each publication confirming Wakefield's thesis reinforced the trust the British placed in him and increased the number of anti-vaccine adherents, as shown in Figure 1 above. The alleged failures of the British government, such as the Leo Blair case, also increased mistrust of the reassuring rhetoric of the authorities. In this context, the minority discourse, instilled by Wakefield and widely disseminated by the media, thus appeared more likely than the majority discourse emanating from the government and the institutions guaranteeing public health. Nor was it a matter of believing without evidence, since Wakefield, O'Leary and Geier \& Geier had all conducted published studies. As non-scientists and non-specialists in the field of gastroenterological disorders, the various stakeholders, such as journalists and the general public, did not have the necessary expertise to weigh the epistemic value of a scientific study according to the methodological choices, analyses and conclusions of the researchers. They then delegated the justification of their beliefs to the trust they placed in the mediator of that belief. However, a prerequisite was necessary: a prior adherence to science. The intellectual path could be summarised as follows:

- I place great value on science and the scientific studies it produces;

- I trust this researcher A;

- I trust the journal B;

- I trust institution C;

- Therefore, I have good reason to support the proposals put forward by researcher A, published in journal $\mathrm{B}$, and working for institution $\mathrm{C}$.

Journalists and other science-minded individuals, for example, placed great value on studies by researchers such as Wakefield, O'Leary, Geier \& Geier, independently of the collective process of knowledge building that took place during the scientific controversy (1998-2004). Where the majority of experts considered Wakefield's conclusions to be wrong from the outset of the controversy, non-scientists did not. The epistemic value attributed to a scientific study was thus higher among non-scientists than among scientists, which explained the difference in the evaluation of Wakefield's thesis. We have also seen that the socio-historical context played a major role in the attribution of the epistemic value of each belief disseminated. In sum, in the absence of evidence to forge adherence, trust and distrust based on individual experience have come together to define the epistemic value of a belief.

This brings us to the final stage of the adherence process translating Wakefield's thesis into the denial of vaccination to parents with young children. Adhering to Wakefield's discourse is one step, translating it into action (whether or not to vaccinate one's child) is another. In order to reduce uncertainty, parents will not limit themselves to scientific or journalistic discourse, but will carry out their own investigations. The epistemic values they define at the end of these steps will be decisive in their decision-making. To facilitate this difficult choice, parents will mobilise other sources collected on the Internet (Kata, 2010), such as testimonials that they can easily access through anti-vaccine sites (Kata, 2010; Ward, Peretti-Watel, Larson, Raude, et al., 2015). These parents explained in great detail, with photos and videos, the behavioural changes their children experienced following vaccination. While the scientific discourse is very distant and conceptual, the parents had what they considered to be evidence to support Wakefield's thesis. As a result, their doubts about the safety of the MMR vaccine increased. The testimony of parents stating that their child's autism had developed following inoculation with the vaccine remains, however, third party mediated evidence (Sauvayre, 2012), which certainly has a higher epistemic value than the government recommendations, but does not have the epistemic value of experiential evidence (Sauvayre, 2012) based 
on one's own sensory and perceptual experience. Parents then had to weigh several sources with equivalent values: parental testimonies and scientific studies. To do so, they mobilised the beliefs and knowledge they had previously accepted. They refined and organised the different sources of information, adjusted their respective epistemic values and made a decision for their children. Parental testimonies collected by McMurray (2004) and his collaborators show how difficult this decision was. In addition, there is evidence that many parents rejecting traditional medicine in favour of alternative medicine agree with Wakefield's thesis. On the epistemic value scale, the dominant scientific discourse and their doctor's injunctions are devalued in favour of testimonials (see Table 1 below).

\section{TABLE 1 \\ EXAMPLE OF EPISTEMIC VALUE SCALES COMPARED BETWEEN SCIENTISTS AND NON-SCIENTISTS}

\begin{tabular}{lll}
\hline Epistemic values & Scientists from Provence & Non-vaccine scientists \\
\hline High & Replicated studies with & Individual sensory and perceptual experiences \\
& confirmed results & \\
Average & Epidemiological studies & Testimonials \\
Low & Clinical studies & Scientific studies \\
None & Varies according to individuals' prior beliefs : \\
& Testimonials & - Governmental discourse \\
& - & Speeches from the pharmaceutical \\
& & industry \\
& & - Traditional medicine \\
& & Epidemiological \\
\end{tabular}

Moreover, when parents had experiential evidence, i.e. observation of their child developing autistic signs following inoculation with the MMR vaccine, there was full agreement with Wakefield's thesis. The parents' observation of their child's behavioural changes then became experiential evidence that ranked highest on the epistemic value scale (see Table 1). The interview study conducted by McMurray (2004) and his collaborators showed that parents who refused all or part of the MMR vaccine (one or two injections) either had children with autism themselves or had people with autism in their close circle. For them, there was no doubt that the MMR vaccine was harmful and that their duty as parents was to protect their children from the neurological disability they were suffering from with this vaccine. The ethics of beliefs and the ethics of parenthood are intertwined: the duties of parenthood serve as a guide to the injunction to evaluate the evidence before adhering to a proposal that will have a lasting impact on the integrity of their child. The trust granted to each party then comes to weigh the epistemic value of the evidence brought. This epistemic scale thus serves as a yardstick for the value judgements made by each party in order to adhere to the proposals most likely to be true.

\section{CONCLUSION}

Clifford's statement that one should not believe without evidence or Alston's adaptation that one should not adhere to beliefs that are likely to be false and that one should only adhere to beliefs that are highly likely to be true puts the notions of evidence and truth at the centre. However, we have seen that during the period 1998-2004, the scientific community disputed the notion of proof by disqualifying the method used by each side. In order to follow the epistemic obligations laid down by Clifford when the evidence itself was not stabilised, scientists and non-scientists alike (journalists, British citizens) erected an epistemic scale of values weighted according to the trust they placed in each source of information. While some gave more credit to epidemiological studies, others gave more credit to clinical studies. Some were entitled to justify their adherence to the provaccine thesis on the basis of the epidemiological studies conducted, while others 
had the same justification by adhering to the anti-vaccine thesis on the basis of the clinical ethics conducted. Moreover, when the scientific community considered from 2004 onwards that the MMR vaccine did not cause autism, it proceeded by attributing a higher epistemic value to epidemiological studies and by devaluing published clinical studies. However, now that the scientific controversy has ended and ruled in favour of the provaccine thesis, one would be tempted to observe the justification of the proponents of Wakefield's thesis under a more irrationalist angle. However, they had good reason to adhere to this thesis in their own context, shaken by scientific controversies, strongly influenced by journalistic discourse and by distrust of government discourse in the wake of the BSE crisis.

This socio-historical case of growing mistrust of vaccines further questions the notion of evidence, which in Clifford's statement seemed to be of obvious objectivity. However, this case has shown that this notion of evidence is not always easy to establish and that the process of adherence is also nourished by the trust placed in mediators of the evidence available to social individuals. The mechanisms of belief are thus grappling with social and cognitive dynamics that lead to differentiated perceptions of evidence. The evidence provided by Wakefield was then collectively discussed, disseminated and led to the adherence of many individuals to the point of seeing the vaccination rate fall globally. However, it was not so much the scientific evidence challenging his anti-vaccine thesis that proved Wakefield right, but rather the ethical failings revealed by journalist Deer and condemned by the GMC. In short, membership was based more on trust in Wakefield. Wakedfield's thesis and the mistrust of the MMR vaccine are nevertheless still alive and questioning for many observers since their adherents seem to believe against the evidence, against the accumulated scientific evidence, but what about their epistemic scale of values?

\section{ACKNOWLEDGEMENT}

Translated \& edited by American Publishing Services (https://americanpublishingservices.com/).

\section{ENDNOTES}

1. This is a translation of an article entitled "Éthique de la croyance, confiance et valeur épistémique. Le cas de la controverse scientifique entourant le vaccin contre la rougeole", previously published in La Revue Française d'Éthique Appliquée peer-reviewed journal with the permission of Éditions Érès.

2. The Lancet was the 2nd largest general medical journal in the world in 1998 and was ranked in the top three between 1997 and 2018 by the Journal Citation Reports (JCR) established by Clarivates Analytics.

3. Studies taken into account in reports published by the Institute of Medicine (2004, 2012). This non-profit organisation, called the National Academies of Sciences, Engineering, and Medicine since 2015, aims to objectively restitute the knowledge accumulated on health issues. The reports they publish at the National Academies Press are recognised and have a global reach (Harris, 2011).

4. Walker-Smith appealed and won.

5. Wakefield said O'Leary provided evidence of the link between the MMR vaccine and autism, which the Irish researcher denied in press reports. However, while Wakefield's statement was widely publicised in the media, O'Leary's statement was only broadcast by the BBC (Fitzpatrick, 2004).

6. According to Web of Science, between 1994 and 1998, Wakefield published 18 articles in JCR-rated journals. $56 \%$ of these articles are ranked in the first quartile of the world's best journals. Over the period 1999-2004, the quality of its publications is increasing: $76 \%$ of the 25 articles it publishes are classified in this first quarter of the best journals.

7. Chamak (2017) notes that parents of autistic children, adhering to the anti-vaccine thesis, disqualify epidemiological studies. 


\section{REFERENCES}

Alston, W.P. (1988). The Deontological Conception of Epistemic Justification. Philosophical Perspectives, 2, 257-299. https://doi.org/10.2307/2214077

Boseley, S. (2002, February). Comment: The MMR vaccination and autism. The Guardian. Retrieved from https://www.theguardian.com/uk/2002/feb/07/society.health

Boudon, R. (2003). Raison, bonnes raisons. Paris: Presses Universitaires de France.

Chamak, B. (2017). L'affaire Wakefield et le mouvement anti-vaccination. Neuropsychiatrie de l'Enfance et de l'Adolescence, 65(8), 469-473. https://doi.org/10.1016/j.neurenf.2017.04.003

Clifford, W.K. (1877). The Ethics of Belief. Contemporary Review.

Cox, A.R. (2003). Re: MMR and Autism: No further delay please. Retrieved from https://www.bmj.com/rapid-response/2011/10/29/re-mmr-and-autism-no-further-delay-please

Deer, B. (2004, February). Revealed: MMR research scandal. The Sunday Times. Retrieved from https://www.thetimes.co.uk/article/revealed-mmr-research-scandal-7ncfntn8mjq

Deer, B. (2011a). How the vaccine crisis was meant to make money. BMJ: British Medical Journal, 342, 136-142. https://doi.org/10.1136/bmj.c5258

Deer, B. (2011b). The Lancet's two days to bury bad news. BMJ, 342, c7001. https://doi.org/10.1136/bmj.c7001

Deer, B. (n.d.). Andrew Wakefield - the fraud investigation. Brian Deer Award-Winning Investigations. Retrieved from https://briandeer.com/mmr/lancet-summary.htm

Elphinstone, P. (2004). MMR and autism: the debate continues. The Lancet, 363(9408), 569. https://doi.org/10.1016/S0140-6736(04)15552-9

Engel, P. (2006). Croyance individuelle. In Dictionnaire des sciences humaines (pp. 223-225). Paris: Presses Universitaires de France.

Fitzpatrick, M. (2004). MMR and Autism: What Parents Need to Know. London: Routledge.

Geier, D.A., \& Geier, M.R. (2004). A comparative evaluation of the effects of MMR immunization and mercury doses from thimerosal-containing childhood vaccines on the population prevalence of autism. Medical Science Monitor, 10(3), 33-39.

Geier, M.R., \& Geier, D.A. (2003). Pediatric MMR Vaccination Safety. International Pediatrics, 18(2), 203-208.

Greif, K.F., \& Merz, J.F. (2007). Current Controversies in the Biological Sciences: Case Studies of Policy Challenges from New Technologies. Cambridge, MA: The MIT Press.

Harris, G. (2011, August). Vaccine Cleared Again as Autism Culprit. The New York Times. Retrieved from https://www.nytimes.com/2011/08/26/health/26vaccine.html

Harvey, P. (2004). MMR and autism: The debate continues. The Lancet, 363(9408), 568. https://doi.org/10.1016/S0140-6736(04)15550-5

Horton, R. (2004). A statement by the editors of The Lancet. Lancet, 363(9411), 820-821. https://doi.org/10.1016/S0140-6736(04)15699-7

Institute of Medicine. (2001). Immunization Safety Review: Measles-Mumps-Rubella Vaccine and Autism. Washington, DC: The National Academies Press. Retrieved from http://nap.edu/10101

Institute of Medicine. (2004). Immunization Safety Review: Vaccines and Autism. Washington, DC: The National Academies Press. Retrieved from http://nap.edu/10997

Institute of Medicine. (2012). Adverse Effects of Vaccines: Evidence and Causality. Washington, DC: The National Academies Press. Retrieved from http://nap.edu/13164

James, W. (1842-1910). (2005). La volonté de croire. (L. Moulin, Trans.). Paris: Les empêcheurs de penser en rond.

Kata, A. (2010). A postmodern Pandora's box: Anti-vaccination misinformation on the Internet. Vaccine, 28(7), 1709-1716. https://doi.org/10.1016/j.vaccine.2009.12.022

Martin, C.M., Uhlmann, V., Killalea, A., Sheils, O., \& O’Leary, J.J. (2002). Detection of measles virus in children with ileo-colonic lymphoid nodular hyperplasia, enterocolitis and developmental disorder. Molecular Psychiatry, 7(2), S47-S48. https://doi.org/10.1038/sj.mp.4001179 
McMurray, R., Cheater, F.M., Weighall, A., Nelson, C., Schweiger, M., \& Mukherjee, S. (2004). Managing controversy through consultation: A qualitative study of communication and trust around MMR vaccination decisions. The British Journal of General Practice, 54(504), 520-525.

Meikle, J. (2003, May). New MMR link to autism, claims study. The Guardian. Retrieved from https://www.theguardian.com/society/2003/may/21/science.medicineandhealth

Millward, G. (2019). Vaccinating Britain. Mass vaccination and the public since the Second World War. Manchester, UK: Manchester University Press. Retrieved from https://www.manchesteropenhive.com/view/9781526126764/9781526126764.00013.xml

Mnookin, S. (2011). The Panic Virus: A True Story of Medicine, Science, and Fear. New York: Simon and Schuster.

Mnookin, S. (2017, July). MMR Vaccine Scare: Andrew Wakefield's Fraudulent Study. The Daily Beast. Retrieved from https:/www.thedailybeast.com/articles/2011/01/13/mmr-vaccine-scare-andrewwakefields-fraudulent-study

Murch, S.H. (2004). MMR and autism: The debate continues. The Lancet, 363(9408), 568-569. https://doi.org/10.1016/S0140-6736(04)15551-7

Murch, S.H., Anthony, A., Casson, D.H., Malik, M., Berelowitz, M., Dhillon, A.P., . . Walker-Smith, J.A. (2004). Retraction of an interpretation. Lancet, 363(9411), 750. https://doi.org/10.1016/S0140-6736(04)15715-2

OCDE. (2019). Taux de vaccination des enfants - Tableau 1980-2018. OCDE.org. https://doi.org/10.1787/82ecfbfc-fr

Payne, C., \& Mason, B. (1998). Autism, inflammatory bowel disease, and MMR vaccine. Lancet, 351(9106), 907. https://doi.org/10.1016/S0140-6736(05)70319-6

Sauvayre, R. (2012). Croire à l'incroyable. Paris: Presses Universitaires de France.

Sauvayre, R. (2017). The rationality of belief change and the unexpected effects of a conflict of values. Rationality and Society, 29(3), 298-321. https://doi.org/10.1177/1043463117717231

The National CJD Research \& Surveillance Unit. (2017). 26th Annual Repport 2017. Creutzfeldt-Jakob disease surveillance in the UK (p.28). Edinbugh: Western General Hospital. Retrieved from http://www.cjd.ed.ac.uk/sites/default/files/report26.pdf

Thrower, D. (2004). MMR and autism: the debate continues. The Lancet, 363(9408), 567-568. https://doi.org/10.1016/S0140-6736(04)15549-9

Uhlmann, V., Martin, C.M., Sheils, O., Pilkington, L., Silva, I., Killalea, A., . . O’Leary, J.J. (2002). Potential viral pathogenic mechanism for new variant inflammatory bowel disease. Molecular Pathology, 55(2), 84-90. https://doi.org/10.1136/mp.55.2.84

Wakefield, A.J. (1998). Autism, inflammatory bowel disease, and MMR vaccine. Lancet, 351(9106), 908. https://doi.org/10.1016/S0140-6736(05)70322-6

Wakefield, A., Murch, S., Anthony, A., Linnell, J., Casson, D., Malik, M., . . Walker-Smith, J. (1998). [Retracted] Ileal-lymphoid-nodular hyperplasia, non-specific colitis, and pervasive developmental disorder in children. The Lancet, 351(9103), 637-641. https://doi.org/10.1016/S01406736(97)11096-0

Ward, J.K., Peretti-Watel, P., Larson, H.J., Raude, J., \& Verger, P. (2015). Vaccine-criticism on the internet: New insights based on French-speaking websites. Vaccine, 33(8), 1063-1070. https://doi.org/10.1016/j.vaccine.2014.12.064

Weber, M. (2003). Le savant et le politique. (C. Colliot-Thélène, Trans.). Paris: La Découverte.

Womack, S. (2001, December 20). Blair silent over Leo's MMR jab. The Telegraph. Retrieved from https://www.telegraph.co.uk/news/uknews/1365829/Blair-silent-over-Leos-MMR-jab.html 